\title{
A Pandemia do novo Coronavírus (COVID-19) e a Divulgação da Ciência no Brasil \\ The Pandemic of the new Coronavirus (COVID-19) and the Dissemination of Science in Brazil
}

\author{
Antoniel dos Santos Gomes Filho ${ }^{1}$; Gislene Farias de Oliveira ${ }^{2}$
}

Desde que um novo coronavírus (COVID-19) foi relatado em Wuhan, na província de Hubei, na China em dezembro de 2019, o mesmo vem se alastrando entre a população mundial, sendo considerado uma pandemia pela Organização Mundial da Saúde (OMS) (XU, 2020; OMS, 2020; HOLANDA, 2020).

Diante da pandemia de COVID-19 o mundo tem acompanhando o desenvolvimento de diversas pesquisas científicas nas mais diversas áreas do conhecimento, em especial nas ciências biológicas, biomédicas e farmacológicas.

Essas pesquisas têm sido noticiadas cotidianamente nos telejornais, jornais, sites especializados, redes sociais, e outros veículos de informações físicos e online. Como tudo, no contexto da pandemia de COVID-19 a divulgação das pesquisas científicas em canais de TV aberta tem sido uma constante nos telejornais, alguns até foram criados para informar os espectadores sobre a pandemia e o andamento das investigações científicas. Pode-se dizer que essa ampla divulgação é algo inédito, no caso Brasileiro, divergindo de outras notícias e estudos que versam sobre a diminuição nos investimentos em educação, em especial na educação superior (SARDINHA; SOUZA, 2019; SILVA, et al. 2019; MARTINS, 2019).

No contexto de pandemia governos e população solicitam da ciência respostas para diminuir os impactos do novo coronavírus, e até mesmo uma cura para o COVID-19, seja

\footnotetext{
${ }^{1}$ Professor do curso de Psicologia do Centro Universitário Vale do Salgado (UniVS) e da Faculdade de Ciências Humanas do Sertão Central (FACHUSC). Doutorando em Ciências da Educação pela Universidade San Carlos (USCPY). Mestre em Educação pela Universidade Federal do Ceará (UFC). Tecnólogo em Gestão Comercial pelo Centro Universitário Dr. Leão Sampaio (UniLeão). Licenciado em Pedagogia pela Faculdade Kurios (FAK). E-mail: antoniel.historiacomparada@gmail.com / antonielsantos@univs.edu.br;

${ }^{2}$ Professora do Curso de Medicina da Universidade Federal do Cariri. Psicóloga, Doutora em Psicologia Social pela Universidade Federal da Paraíba. E-mail: gislene.farias@ufca.edu.br. 
através de um medicamento já disponível, um novo medicamento ou vacina. Mas, como visto no caso brasileiro, os investimentos em ciência e tecnologia tem sido afetados nos últimos tempos, impactando diretamente nas pesquisas sobre o novo agente infecioso. Todavia, mesmo diante dessas adversidades cientistas brasileiros tem realizados investigações sobre o novo coronavírus, sendo estas amplamente divulgadas, como pode-se observar nas seguintes matérias jornalísticas: Quem são as brasileiras que sequenciaram o genoma do novo coronavírus (G1, 2020); Conheça as cinco pesquisadoras que sequenciaram o genoma do coronavírus (CORREIO BRAZILIENSE, 2020); Entidades repudiam ameaças a pesquisadores de estudo com cloroquina em Manaus (UOL, 2020).

As revistas científicas nesse momento, vem organizados números especiais e dossiês sobre o novo contexto do COVID-19. É necessário destacar que além das contribuições oriundas das ciências biológicas, biomédicas e farmacológicas, é de fundamental importância a contribuição das ciências humanas, sociais e sociais aplicadas para que se possa compreender os efeitos da pandemia de COVID-19. Estudos como os de Macedo, Ornellas e Bomfim (2020; 2020a), Cueto (2020), Macário e Reis (2020), Maranhão (2020), são exemplos de investigações nesses campos do conhecimento. A divulgação dessas pesquisas e investigações também precisam ocorrer nas mídias já mencionadas, para que as pessoas possam conhecer as diversas realidades sociais e econômicas que as diversas regiões brasileiras, vem passando no contexto do novo coronavírus.

\section{Fake News}

São muitas as falsas notícias, as novidades maquiadas, os boatos, com o intuito de obter a atenção do leitor em época de maiores dificuldades sociais. O ambiente de pandemia é muito propício para tais manchetes, levando-se em conta que a população fica ávida por informações coerentes e, por isso, mais vulnerável às chamadas Fake News. São geralmente notícias desagradáveis, normalmente falseadas sobre o que há de mais comentado no momento. Neste momento, os políticos e toda a situação social que envolve o COVID-19.

Uma Fake News pode ser definida como como "artigos noticiosos que são intencionalmente falsos e aptos a serem verificados como tal, e que podem enganar os leitores" (ALLCOTT e GENTZKOW, 2017, p.4). 
Na realidade, é uma informação que não condiz com a verdade, ou que levanta incerteza, com a finalidade de obter-se algum benefício financeiro. São preocupantes pois avançam as redes sociais causando danos aos seus consumidores.

O ambiente on line parece ser facilitador da disseminação por conta da velocidade com que uma informação circula. Daí a grande necessidade de que os periódicos científicos aceitem trabalhos que sejam condizentes com essa demanda social, por informação consonante.

Ante uma problemática mundial tão séria, como é a do Coronavírus, ainda ter que nos deparar com mecanismos cada vez mais sofisticados de disseminação de falsas informações é desolador para os pesquisadores e colaboradores da academia.

É preciso que, cada vez mais, haja incentivo político a leis que possam minimizar os estragos perpetrados pelas informações desencontradas com a realidade e com a ciência, de forma a coibir perfis, sites e plataformas, seja com cortes de incentivos financeiros ou outro mecanismo aos que disseminam notícias falsas.

Trata-se pois, de um assunto que carece de maior aprofundamento, as questões relacionadas ao combate às notícias falsas, visto que, os próprios políticos, seja no Brasil ou nos Estados Unidos o tem utilizado em época eleitoral. Portanto não é algo que se resolva com fórmulas simples e prontas. É necessário que se lance mão de um conjunto de ferramentas e logística associada, que vão desde recursos técnicos até o investimento em educação e aprofundamento digital. Quem sabe, restrições legais devam ser implementadas para se combater a desinformação, sem perder de vista o desafio de respeitar a liberdade de expressão.

Portanto, o acesso e divulgação as informações sobre o novo coronavírus emitidos pelos meios de comunicação, em especial os de TV aberta que atingem a maioria da população brasileira, devem estar embasadas nas pesquisas científicas que prezam pela qualidade técnica e responsabilidade ética. Desse modo pode-se promover o conhecimento científico na sociedade brasileira.

\section{Referências}

ALLCOTT, H., e GENTZKOW, M. Social media and fake news in the 2016 election (No. w23089). National Bureau of Economic Research, 2017.

CORREIO BRAZILIENSE. Conheça as cinco pesquisadoras que sequenciaram o genoma do coronavírus. 2020. 
CUETO, Marcos. O que um historiador da saúde tem a dizer sobre a pandemia do novo coronavírus (Covid-19)? Entrevista de Marcos Cueto a Bruno Leal. Café História - História feita com cliques. 2020. [Repositório Institucional da Fiocruz].

G1. Quem são as brasileiras que sequenciaram o genoma do novo coronavírus. 2020.

HOLANDA, Vanderlan Nogueira. Pandemia de COVID-19 e os esforços da ciência para combater o novo coronavírus. Revista Interfaces: Saúde, Humanas e Tecnologia, v. 8, n. 1, 2020.

MACÁRIO, Epitácio.; REIS, Luiz Fernando. COVID-19, dívida pública e crise de financiamento de ciência e tecnologia no Brasil. Auditoria Cidadã, 2020.

MACEDO, Yuri Miguel.; ORNELLAS, Joaquim Lemos.; BOMFIM, Helder Freitas do. COVID 19 NO BRASIL: o que se espera para população subalternizada? Revista Encantar - Educação, Cultura e Sociedade, v. 2, 2020.

MACEDO, Yuri Miguel.; ORNELLAS, Joaquim Lemos.; BOMFIM, Helder Freitas do. COVID19 nas favelas e periferias brasileiras. Boletim de Conjuntura (BOCA), v. 2, n. 4, 2020a.

MARANHÃO, Romero de Albuquerque. A violência doméstica durante a quarentena da COVID19: entre romances, feminicídios e prevenção. Brazilian Journal of Health Review (BJRH), v. 3, n. $2,2020$.

MARTINS, Vinicius. Educação, ciência e tecnologia: como desenvolver o Brasil sem investimento? Revista Thema, v. 16, n. 1, 2019.

OMS. Brote de enfermedad por coronavirus (COVID-19). 2020.

SARDINHA, Rafaela Campos.; SOUZA, Marcelo Lopes de. Gastos Públicos em Educação no Brasil 2013 a 2016. Cadernos de Estudos e Pesquisas em Políticas Educacionais, v. 2, 2019.

SILVA, Fabrício Rodrigues da. et al. O Financiamento das Universidades Federais no Brasil em tempos de ajuste fiscal: crítica as implicações. Revista Encontros Científicos FVS, v. 1, n. 2, 2019.

UOL. Entidades repudiam ameaças a pesquisadores de estudo com cloroquina em Manaus. 2020.

XU, Bo. et al. Epidemiological data from the COVID-19 outbreak, real-time case information. Nature, Sci Data 7, n. 106, 2020. https://doi.org/10.1038/s41597-020-0448-0.

\section{Como citar este artigo (Formato ABNT):}

GOMES FILHO, Antoniel dos Santos; OLIVEIRA, Gislene Farias de. A Pandemia do novo Coronavírus (COVID-19) e a Divulgação da Ciência no Brasil. Id on Line Rev.Mult. Psic., Maio/2020, vol.14, n.50, p. 509-512. ISSN: 1981-1179. 